\title{
BEHAVIOR OF INDUSTRIAL SECTORS EARNINGS GROWTH RATES IN THE UNITED STATES
}

\author{
Edward Nissan and George Carter*
}

\begin{abstract}
The long-run equilibrium of the competitive model of the economy predicts that per capita income across industries and regions becomes equalized over time. Since earnings constitute a substantial part of income, that model predicts that earnings per person also equalizes over time. During the 1980 s, state and regional income in the United States diverged, thereby contradicting the competitive model hypothesis as well as Simon Kuznets's hypothesis of income equality varying directly with economic development. This paper examines earnings growth rates of 10 industrial sectors by using actual state data for 1969-88 and projected state data for 1988-2000. Even though the findings indicate overall convergence in growth rates based on state data, continued average inequality between regions persists.
\end{abstract}

\section{INTRODUCTION}

Differences in regional growth and development and their consequent effect on income inequality is a subject of great interest. Lewis (1993) gives a summary of the elements that may explain the level of aggregate and per capita income in a region. He states that such factors as the export base, which includes primary, secondary, and tertiary exporting industries; investment and government expenditures; and adequacy of supply-side factors such as land, labor, and capital are important determinants. Kubin and Steiner (1992) classify regions according to forms of economic behavior where economic agents may behave in a creative, entrepreneurial way or in an allocative, adaptive way in part as a consequence of cyclical, evolutionary sequence. Added to these are the advantages gained from the location of various economic activities in specific geographical areas.

Yet, despite regional disparities, Kuznets (1955) theorized the inverted U model where income inequality rises in the early stages of development and declines in the later stages of development with eventual stabilization, a model of income inequality that contrasts less developed nations with developed nations. Eventual stabilization of income inequality results from the market mechanism explained by the neoclassical approach. Armstrong and Taylor (1985) contend that the neoclassical approach anticipates an equilibrium in income and employment. This may be the result of outward migration from regions of excess labor

\footnotetext{
*Professor and Associate Professor, Department of Economics and International Business, The University of Southern Mississippi. The authors would like to thank anonymous referees and the editors of this journal for helpful comments and suggestions on an earlier draft of this paper.
} 
supply; also, because regions of excess labor supply become more attractive to investors, we may witness "trickling-down effects" as described by Alonso (1968), or even a combination of the two.

Kuznets's inverted U hypothesis has been subjected to numerous empirical studies, one of the earliest of which was the classic work by Williamson (1965), which gave credence to Kuznets's hypothesis. In recent years, research by Amos $(1988,1989,1991)$ questioned the validity of the inverted $U$ hypothesis and proposed instead an "augmented" inverted U. According to the excellent summary by McGillivray and Peter (1991), Amos contends that the increase-decrease pattern of the inverted U should be an increase-decrease-increase pattem. McGillivray and Peter, though, in agreement with Amos that regional growth rates are not likely to equalize, dispute Amos's methodology and contend that the smallness of his sample provides inadequate proof of a renewed Kuznets cycle. On the other hand, recent work by Ram $(1991,1992)$ supports Amos by finding that income inequality does not monotonically decline in the United States, a highly developed country. Similarly, Nelson (1984) gives further support to Amos's contention by pointing out that economic opportunities in some areas may contribute to a rise in inequality even though differences in eamings between low- and middle-income groups decline.

Amos (1991) empirically investigated the causes of income differentials by using the contribution of industrial sectoral growth as an explanation. He used linear and quadratic equations, which regressed average per capita real gross state product growth rate from 1963 to 1986 against the per capita real gross state product in 1963 for each of 10 sectors. The sectors included were agriculture, forestry, and fishery; mining; construction; manufacturing; transportation, communications, and public utilities; wholesale trade; retail trade; finance, insurance, and real estate; services; and government.

This paper extends Amos's work by examining convergence of growth rates of earnings of the same 10 industrial sectors using states' data and addresses the question of equality of regional rates of growth for the periods 1969-1979 and 1979-1988 and for projections of the period 1988-2000. Earnings are particularly important. In 1988, according to Rowley, Redman, and Angle (1991), they accounted for approximately 69 percent of per capita income, and as Browne (1989) points out, earnings have played a primary role in the divergence of regional incomes since the late 1970s, a conclusion substantiated by Rowley, Redman, and Angle (1992).

Data for growth in earnings by place of work measured in dollars of constant purchasing power were obtained from the Bureau of Economic Analysis (BEA 1980) and the projections from Johnson, Kort, and Friedenberg (1990). The projections for eamings to the year 2000 are obtained through a set of complex 
econometric models and the use of extensive past data through 1988. The procedure entails the projection of historical trends of a state's earnings per employee in an industry as a percent of national earnings. The resulting measure is multiplied by projected national earnings per employee in the industry and then multiplied by projected state employment in the industry to yield a final projected state earnings in the industry. If the explanations provided by Lienesch and Kort (1992) can serve as a guide for understanding recent methodology used by BEA in calculating trends, then the primary detailed data used for state eamings in recent years are remarkably superior to those used previously. They further explain that while the bottom-up method, whereby variables projected in the state models were aggregated to obtain national projection, was used in earlier work, the current methodology uses a hybrid approach in which national variables link up with the state projection in a top-down manner where the effect of the national economy is reflected in the state economies. As a consequence of this hybrid approach, changes in an individual state economy both affect and are affected by changes in the national economy.

While the interest in convergence, as advocated by the neoclassical as well as the Kuznets inverted U models, is concerned with levels of income, growth of income and, by implication, growth of earnings play a key role in attaining convergence. The neoclassical growth model predicts, according to Barro and Sala-i-Martin (1991, 1992), that poorer economies with lower values of capital per unit of effective labor (number of workers adjusted for the effect of technical progress) tend toward faster growth in per capita income.

Perhaps this is because of their potential to follow and to imitate, or as Romer (1993) puts it, use ideas borrowed from industrialized countries and from these ideas create new ideas for products to be sold abroad. In particular, Barro and Sala-i-Martin indicate that in the United States, in regard to state per capita personal income (the return to the factor owners) or gross state product (GSP) per capita (gross market value of goods and services of labor and property in a state), the poorer states grow faster in these categories, reflecting higher labor productivity in the various industrial sectors. State average income of the industrial sectors therefore tends toward convergence. They conclude that the evidence is in favor of convergence for the industrial sectors as well as state aggregates.

In their study of income convergence of OECD countries since 1950, Dowrick and Nguyen (1989) are in agreement with Barro and Sala-i-Martin regarding the notion that rapid growth is more prevalent among countries that start off technologically backward. This rapid growth is accomplished through a process of catching up in levels of total factor productivity (technological progress estimated by capital stock growth) or labor productivity (the marginal 
product of labor), both of which may explain tendencies of income levels toward convergence.

Convergence of state per capita income for which the neoclassical or the Kuznets inverted $U$ theories are applied may also apply for the industrial sectors, a line of thought followed by Amos (1991) and Carlino (1992). In either case, one needs to investigate both levels and growth. The underlying rationale for using growth rates to test for convergence, as pointed out by McGillivray and Peter (1991), is that for convergence to occur, growth rates must equalize, and relative mean incomes must remain unchanged. This paper examines the question of convergence of earning growth rates. Growth in earnings of the industrial sectors (where data is based on state earnings per employee) is customarily used in lieu of the growth either in labor productivity or in total factor productivity of the industrial sectors, an approach followed by Branson and Monoyios (1977) and Niroomand (1991) where they measure growth in human capital by earnings differentials to reflect factor productivity.

Summary information on averages and standard deviations for earnings growth rates are provided in Table 1. For most industrial sectors, average growth was smaller during the period 1979-1988 than in the previous decade. The only sector that had larger growth in 1979-88 than in 1969-79 was the services sector. For the projected period 1988-2000, there are some instances of improvement when compared to the 1979-88 decade, as, for example, the mining sector where the growth rate is $\mathbf{0 . 7 4}$, as compared to -3.79 . In general, average growth rates for 1979-1988, as well as the projected average growth rates for 1988-2000, are much smaller than in the period 1969-1979. The standard deviations provide measures of variation in the states' growth rates. Table 1 shows that the standard deviation in 1979-88 was smaller in five instances, almost equal in three instances, and larger, implying more volatility, in two instances as compared to 1969-1979. For $1988-2000$, the variation declined substantially for all sectors.

\section{CONVERGENCE OF GROWTH RATES}

In order to ascertain the convergence of growth rates, data on states' growth rates for 1979-1988 were regressed on data of the previous period 1969-1978, and in tum, the data in the projected period 1988-2000 were regressed on the corresponding data of the former period 1979-1988. The scheme follows a methodology pursued by Hart and Pearce (1986) in their research on growth patterns of large enterprises and by Congdon and Shepherd (1988) for effect of change in the urban social environment. 
TABLE 1

Annual Average Growth Rates of State Earning of Industrial Sectors

\begin{tabular}{|c|c|c|c|c|c|c|}
\hline \multirow[b]{2}{*}{ Variables } & \multicolumn{2}{|c|}{$1969-1979$} & \multicolumn{2}{|c|}{$1979-1988$} & \multicolumn{2}{|c|}{$1988-2000$} \\
\hline & Mean & $S D^{1}$ & Mean & $S^{1}$ & Mean & $S D^{1}$ \\
\hline Agriculture & 4.05 & 3.13 & 2.80 & 2.40 & 3.08 & 0.67 \\
\hline Mining & 6.33 & 4.15 & -3.79 & 3.40 & 0.74 & 0.66 \\
\hline Construction & 3.63 & 3.70 & -0.07 & 4.39 & 1.49 & 0.72 \\
\hline Manufacturing & 3.20 & 2.26 & 0.01 & 1.81 & 1.40 & 0.58 \\
\hline Transportation & 4.60 & 1.89 & 0.82 & 1.71 & 1.77 & 0.45 \\
\hline Wholesale trade & 5.23 & 2.39 & 1.15 & 2.52 & 1.58 & 0.54 \\
\hline Retail trade & 2.74 & 1.98 & 0.86 & 2.08 & 1.90 & 0.43 \\
\hline FIRE & 4.79 & 2.03 & 2.71 & 2.43 & 2.35 & 0.49 \\
\hline Services & 4.73 & 1.55 & 5.20 & 1.71 & 3.22 & 0.39 \\
\hline Government & 3.31 & 1.18 & 1.98 & 0.94 & 1.20 & 0.33 \\
\hline
\end{tabular}

ISD is standard deviation.

Note: Agriculture includes forestry and fisheries; transportation includes public utilities; and FIRE stands for finance, insurance, and real estate.

This model is based on the notion that observed values on the same state made over two separate occasions with score $\mathrm{x}$ in the former occasion and a score $y$ in the later occasion jointly follow a bivariate normal probability law if both are individually normal. There are five parameters in the bivariate normal density function: $\mu_{x}, \mu_{y}, \sigma_{x}>0, \sigma_{y}>0$, and $-1<\rho<1$. The first two symbols stand for expected values for $X$ and $Y$, the next two symbols are the respective standard deviations, and $\rho$ is the correlation between $X$ and $Y$. It follows, according to Larson (1982), that the conditional distribution for $\mathrm{Y}$, given $\mathrm{X}=\mathrm{x}$ is normal with mean

$$
E[Y \mid X=X]=\mu_{Y}+\rho\left(\sigma_{y} / \sigma_{X}\right)\left(X-\mu_{X}\right)
$$

written in a simplified form as

$$
E[Y \mid X]=\mu_{Y}+\beta\left(X-\mu_{x}\right),
$$

and estimated by least squares as 


$$
Y_{i}^{\prime}=\bar{Y}+b\left(X_{i}-\bar{X}\right)
$$

where $Y_{i}^{\prime}$ is an estimator of the conditional mean $\mathrm{E}[\mathrm{Y} \mid \mathrm{x}]$ obtained by regressing $\mathrm{Y}$ on $\mathrm{X}$, and $\bar{Y}$ is the observed estimator of $\mu \mathrm{Y}$, which is the average growth rate of an industrial sector in a later period. $X_{i}$ is an observed value, and $\bar{X}$ is the observed average, which is an estimator of $\mu_{\mathrm{x}}$ in a former period. ${ }^{1}$ A divergence away from the mean is implied if $|b|>1(b>1$ or $b<-1)$ because the difference $\left(\mathrm{X}_{\mathrm{i}}-\bar{X}\right)$ becomes larger in absolute terms when $\mathrm{b}>1$ or $b<-1$. Convergence toward the mean occurs when $-1<b<1$. As Creedy (1985) puts it, there is an egalitarian tendency in that $X_{i}$ approaches $\bar{X}$, and therefore the difference $\left(X_{i}-\bar{X}\right)$ becomes smaller in absolute terms. ${ }^{2}$

Table 2 shows the regression results for the 10 sectors. For convenience of display, the symbol "I" is used for regressing 1979-88 growth rates (Y) on the corresponding values (X) in 1969-79. Similarly, "II" stands for the regressions of

TABLE 2

List of Regression Equations of Average Annual Growth Rates of State Earnings of Industrial Sectors

\begin{tabular}{|c|c|c|c|c|c|c|c|c|}
\hline \multirow[t]{2}{*}{ Variables } & \multicolumn{2}{|c|}{$\begin{array}{c}\text { Intercept } \\
\mathbf{a}\end{array}$} & \multicolumn{2}{|c|}{$\begin{array}{c}\text { Slope } \\
\text { b }\end{array}$} & \multicolumn{2}{|c|}{$t$-value } & \multicolumn{2}{|c|}{$\mathbf{r}$} \\
\hline & I & II & $I$ & II & I & II & I & II \\
\hline Agriculture & 2.73 & 3.09 & -0.02 & -0.01 & -0.16 & -0.12 & -0.02 & -0.02 \\
\hline Mining & -3.09 & 0.96 & -0.07 & 0.06 & -0.57 & $2.14^{*}$ & -0.09 & $0.29 *$ \\
\hline Construction & 2.93 & 1.49 & -0.83 & -0.06 & $-6.79 *$ & $-3.03 *$ & $-0.70^{*}$ & $-0.40^{*}$ \\
\hline Manufacturing & -0.38 & 1.40 & 0.12 & 0.15 & 1.07 & $3.82^{*}$ & 0.15 & $0.48^{*}$ \\
\hline Transportation & 0.43 & 1.63 & 0.08 & 0.17 & 0.65 & $6.01^{*}$ & 0.09 & $0.65^{*}$ \\
\hline Wholesale trade & 2.03 & 1.47 & -0.17 & 0.09 & -1.12 & $3.23^{*}$ & -0.16 & $0.42^{*}$ \\
\hline Retail trade & 0.86 & 1.83 & 0.00 & 0.09 & 0.00 & $3.22^{*}$ & 0.00 & $0.42 *$ \\
\hline FIRE & 5.14 & 2.28 & -0.51 & 0.03 & $-3.28^{*}$ & 0.96 & $-0.42 *$ & 0.14 \\
\hline Services & 6.10 & 2.62 & -0.19 & 0.12 & -1.23 & $4.09 *$ & -0.17 & $0.50^{*}$ \\
\hline Government & 1.75 & 0.92 & 0.07 & 0.14 & 0.62 & $3.11 *$ & 0.08 & $0.41^{*}$ \\
\hline
\end{tabular}

Note: "I" refers to results of regressing 1979-88 states' growth rates on corresponding $1969-78$, while "II" similarly refers to regressing $1988-2000$ on 1979-88. Agriculture includes forestry and fisheries; Transportation includes public utilities; and FIRE stands for finance, insurance, and real estate.

*Significant at .05

Source: Computations from Equation (2). 
1988-2000 on 1979-88. The first two columns of Table 2 contain the intercepts " $a$," where $a=\bar{Y}-b \bar{X}$ from Equation (2). The slopes of the regression " $b$ " follow in the next two columns. The succeeding two columns give the t-values for testing the slope " $b$ " for significance, and the last two columns give "r," the estimates of the correlation coefficient " $\rho$." In all instances, $-1<b<1$, positive and significant in seven cases, negative and significant in three cases, and not significant in eight cases, indicating an overall tendency toward convergence of growth rates.

The smallness of the statistically significant coefficients for " $b$ " (negative or positive) and nonsignificance in some instances provide, in the context of this model, a strong evidence for convergence of growth rates. In essence, "b" measures the magnitude of change of the rates between two periods, and its smallness or nonsignificance indicates that in Equation (2) the contribution of $b(X-\bar{X})$ is small and therefore $Y^{\prime} \approx \bar{Y}$. In other words, states' growth rates in earnings, though different, have the tendency to approach the average $\bar{Y}$. It is this tendency for growth rates to approach the average that gives meaning to the notion of convergence. A consequence of this finding is that the gaps in earnings in the various sectors will tend to equalize or stabilize because of the catching-up in growth rates made by the states with below average growth in earnings $\left(X_{i}<\bar{X}\right)$ and the dampening effect on states with above average growth $\left(\mathrm{X}_{\mathrm{i}}>\overline{\mathrm{X}}\right)$. This conclusion is in line with that reached by Barro and Sala-i-Martin $(1991,1992)$ in that, in past decades, states with per capita incomes below the national average grew initially faster than states with higher than average per capita incomes, resulting in narrowing of the gaps in their incomes in later years. This narrowing of gaps (convergence) will be stable if the growth rates themselves converge. Stability in levels of income is therefore assured. ${ }^{3}$

A final look at Table 2 concerns the estimates of the correlation coefficient " $r$ " tested for significance $\left(H_{0}: \rho=0\right)$ by $t=(n-2)^{1 / 2} r /\left(1-r^{2}\right)^{1 / 2}$. Nonsignificance indicates that the two variables $\mathrm{X}$ and $\mathrm{Y}$ are independent. In this regard, no more is known about the occurrence of $Y$ after $X$ is known to have occurred. When " $r$ " is positive and relatively high, the indication is a permanence of hierarchy; states with high growth rates and those with low growth rates in an earlier period have maintained their relative positions. Transportation and public utilities (regression II) is an example. When " $r$ " is negative and relatively large, as in Construction (regression I), the implication is that some changes in relative position have taken place. 


\section{REGIONAL INEQUALITY IN GROWTH RATES}

Even though growth rates of eamings were shown to converge, inequality in regional average growth rates may persist, as evident from the discussion provided in Section II. The convergence in rates implied from Equation (2) says that states with growth rates above and those below the average tend to approach the average when $-1<b<1$. Therefore, when looking at regional averages, it is possible that one region contains many states with above average growth, and another region contains many states with below average, and therefore the difference between the two regional averages may be statistically significant as measured by a t-test.

An extension of the t-test for the differences between more than two means is provided by analysis of variance performed for the three periods under consideration for each of the 10 sectors. If the F-test is statistically significant, then at least two means differ, and a multiple comparison procedure helps to identify which means differ. The method of least-significant-difference outlined by Miller (1985) is used. The groupings of states into regions follow the BEA classification. ${ }^{4}$

The listing of regions in ascending order of growth rates as a consequence of the multiple comparisons, as well as the p-values of the F-tests, is shown in Table 3. A p-value signifies how much agreement there is between the data and the null hypothesis that the eight regional means are all equal. In other words, it is a measure of the credibility of the null hypothesis; the smaller the p-value, the less credible is the null hypothesis. The conclusion to be drawn from the listing is that any two regions that are not inside the same parentheses differ from each other.

If a statistical significance of 5 percent is used as a basis of decision to reject the null hypothesis, 21 out of a possible 30 tests indicate that average regional growth rates differed, even though there was a great deal of overlapping of regions in common subsets, indicating that average rates have a strong tendency to similarity. Of interest are the changes in the rank order of some regions, perhaps as a consequence of differential changes in energy prices in recent years as pointed out by the extensive work on this subject by William Miemyk. In a selection of works, Miemyk $(1977,1982,1984,1985)$ addressed the issue of the response on rising energy prices of relocation of economic activity of marketoriented industries from energy-deficit regions to energy-surplus regions. Miemyk explains the shift as resulting from favorable terms of trade for the energy-surplus regions affecting the manufacturing sector as well as the other industrial sectors such as services, construction, retail, and the like.

To this end, Miernyk chooses standard federal regions ${ }^{5}$ (SFRs) for delineation. He points out that none of the SFRs is entirely composed of energy-surplus 
TABLE 3

Multiple Comparisons of Regional Average Annual Growth Rates of Eamings of Industrial Sectors

\begin{tabular}{|c|c|c|}
\hline Variable & Comparisons & p-value \\
\hline \multicolumn{3}{|c|}{ Agriculture, Forestry, and Fisheries } \\
\hline 1969-1979 & {$[(6,2,5) ;(2,5,1,3) ;(5,1,3,7,8) ;(4)]$} & .0001 \\
\hline 1979-1988 & {$[(6,8,7,4,3,5) ;(5,2) ;(2,1)]$} & .0005 \\
\hline $1988-2000$ & {$[(1,2,6) ;(2,6,4,3,5) ;(6,4,3,5,8,7)]$} & .0104 \\
\hline \multicolumn{3}{|l|}{ Mining } \\
\hline 1969-1979 & {$[(2,1,6,5) ;(1,6,5,4,7,3,8)]$} & .2554 \\
\hline $1979-1988$ & {$[(2,5,6,8,1,7,3) ;(4)]$} & .0500 \\
\hline $1988-2000$ & {$[(7,8,6,2,5,3) ;(8,6,2,5,3,1) ;(5,3,1,4)]$} & .0630 \\
\hline \multicolumn{3}{|l|}{ Construction } \\
\hline 1969-1979 & {$[(1,2,5) ;(3,6,4,7) ;(7,8)]$} & .0000 \\
\hline $1979-1988$ & {$[(8,6,7) ;(6,7,5,4) ;(7,5,4,3) ;(2) ;(1)]$} & .0000 \\
\hline $1988-2000$ & {$[(1,2) ;(2,3) ;(3,5,6,4,8,7)]$} & .0018 \\
\hline \multicolumn{3}{|l|}{ Manufacturing } \\
\hline 1969-1979 & {$[(2,1,5) ;(5,3,6) ;(3,6,4,7,8)]$} & .0000 \\
\hline $1979-1988$ & {$[(5,8,2,6) ;(8,2,6,3,4,1) ;(2,6,3,4,1,7)]$} & .1160 \\
\hline $1988-2000$ & {$[(2,1,5) ;(3,6,4,7,8)]$} & .0002 \\
\hline \multicolumn{3}{|c|}{ Transportation and Public Utilities } \\
\hline 1969-1979 & {$[(2,5,1) ;(5,1,6) ;(6,3,4) ;(3,4,8,7)]$} & .0000 \\
\hline 1979-1988 & {$[(6,8,5,4,2,7) ;(4,2,7,3,1)]$} & .0357 \\
\hline $1988-2000$ & {$[(2,6,5,8,3,1) ;(8,3,1,4,7)]$} & .0575 \\
\hline \multicolumn{3}{|l|}{ Wholesale Trade } \\
\hline 1969-1979 & {$[(2,5,1) ;(5,1,3,4) ;(1,3,4,6) ;(3,4,6,7,8)]$} & .0011 \\
\hline 1979-1988 & {$[(8,6,7,5) ;(6,7,5,3) ;(7,5,3,4,2) ;(1)]$} & .0003 \\
\hline $1988-2000$ & {$[(6,2,5,3,1) ;(2,5,3,1,4) ;(3,1,4,8,7)]$} & .0488 \\
\hline \multicolumn{3}{|l|}{ Retail Trade } \\
\hline 1969-1979 & {$[(2,5,6,1) ;(3,8,7) ;(8,7,4)]$} & .0000 \\
\hline 1979-1988 & {$[(8,6,5) ;(5,7,4,3) ;(7,4,3,2) ;(1)]$} & .0000 \\
\hline $1988-2000$ & {$[(5,6,2,3,1) ;(6,2,3,1,4) ;(2,3,1,4,8,7)]$} & .0849 \\
\hline \multicolumn{3}{|c|}{ Finance, Insurance, and Real Estate } \\
\hline 1969-1979 & {$[(2,5,1,6) ;(5,1,6,3) ;(3,7,8) ;(7,8,4)]$} & .0000 \\
\hline 1979-1988 & {$[(8,4,6) ;(4,6,5,7,3) ;(2,1)]$} & .0000 \\
\hline $1988-2000$ & {$[(5,3,1,6,2,4) ;(3,1,6,2,4,7,8)]$} & .2582 \\
\hline \multicolumn{3}{|l|}{ Services } \\
\hline 1969-1979 & {$[(2,5,1) ;(5,1,6,3,7) ;(7,8) ;(8,4)]$} & .0000 \\
\hline 1979-1988 & {$[(8,6,5,4) ;(6,5,4,3,7) ;(5,4,3,7,2) ;(3,7,2,1)]$} & .0023 \\
\hline $1988-2000$ & {$[(5,2,6,1,3,8,4) ;(3,8,4,7)]$} & .1985 \\
\hline \multicolumn{3}{|l|}{ Government } \\
\hline 1969-1979 & {$[(1,2,6,5,4) ;(2,6,5,4,3,7) ;(4,3,7,8)]$} & .0334 \\
\hline 1979-1988 & {$[(5,6,2,8,4,3) ;(4,3,1,7)]$} & .0702 \\
\hline $1988-2000$ & {$[(2,6,5,1,3,8,4) ;(3,8,4,7)]$} & .1914 \\
\hline
\end{tabular}

Note: The numbers in the table refer to regions as follows: (1) New England,

(2) Mideast, (3) Southeast, (4) Far West, (5) Great Lakes, (6) Plains, (7) Southwest, and

(8) Rocky Mountain. P-value is the smallest level for which the test statistic F is significant. $P$-value $\leq .05$ indicates significance at the 5 percent level. See Endnote 4 for a listing of states in each region. 
states. Of the SFRs, the Southwest and Rocky Mountain-Northem Plains regions, however, may qualify. Their energy surpluses (production minus consumption) in 1979 were 29.51 percent and 6.85 percent of the U.S. total. The states included in these two regions are fairly comparable to the BEA's classification of states of the Southwest and Rocky Mountain designated by the numbers "7" and "8," respectively, in the multiple comparisons shown in Table 3. The results of the table are consistent with the predictions made by Miemyk in that the Southwest (region 7) and Rocky Mountain (region 8) occupied generally the top positions in the hierarchy of growth in eamings for every sector during the early period 1969-79 and the projected period 1988-2000. For the intermediate period 1979-88, no such pattem is evident. In fact, these two regions are placed in the lower hierarchy in most categories. The change in regional ordering coincides with changes in the time periods. Energy prices rose considerably during the 1970s, which made it difficult for residents and businesses in energy-deficit industrial regions such as New England, Mideast, and Great Lakes, to cope. The increase in the cost of residential energy may have initiated the migration of people to the South and Southwest, which affected market-oriented activities including those that are not energy intensive.

The collapse of OPEC and the energy bust during the 1980s resulted in a decline of energy prices, especially oil, which hit hardest the Southwest and Rocky Mountain regions, causing them to lose in the process the favorable terms of trade enjoyed in the earlier decade. Growth in earnings declined for the Southwest and Rocky Mountain regions in all market-oriented activities. On the other hand, New England, the Mideast, and to a certain extent the Southeast and Far West, designated by the numbers "1," "2," "3," and "4," respectively, in Table 3, ranked the highest in growth in most sectors. This was perhaps the result of the location of high-technology industries, such as electronic computing equipment, semi-conductors and related services, and computer software, in these regions as pointed out by Park and Lewis (1991). However, in the projected period 19882000 , the energy-surplus regions are anticipated to recapture the favorable position enjoyed during the $1969-79$ period. There is no reason to deny the possibility that energy prices will rise again, bringing about a new imbalance in interregional terms of trade, a predication also supported by Miernyk.

\section{SUMMARY}

The focus of this paper is a comparison of performance in 10 industrial sectors for base periods 1969-79 and 1979-88 and a projected period 1988-2000. States' annual growth rates of eamings were examined to address the issue of 
convergence and whether patterns of growth between regions are becoming more alike or more different, finding convergence of rates and inequality in average between regions.

The period for which actual data were used (1969-1988) coincides approximately with a period of substantial slowdown in growth in U.S. production which is relevant to growth in earnings and vice versa. According to Lawrence (1988), growth in production declined from 2.1 to 1.2 percent after 1973 with a similar fall in the growth of per capita spending up to 1979. However, between 1979 and 1987, the growth of per capita spending exceeded the growth of per capita production-1.6 percent against 1.2 percent-a difference Lawrence attributed to a large rise in overseas borrowing. The period 1988-2000 contains projections based on extensive available data through 1988 and on the customary assumptions regarding the future. Whether the near future holds to these projections depends on implemented economic policies coinciding with the assumptions made for the projections.

\section{ENDNOTES}

1. When $\mathrm{X}$ and $\mathrm{Y}$ are jointly distributed as, for instance, by a bivariate normal law, and information on $\mathrm{X}$ is available, the distribution $\mathrm{Y}$ changes to a conditional distribution from which the conditional mean (expectation), E[Y|x], is calculated as in Equation (1). If there are two or more possible observed values for $Y$ for a given $x$, that is when $Y$ is sampled from a subpopulation on which the conditional distribution of $\mathrm{Y}$ given $\mathrm{X}=\mathrm{x}$ is defined, the conditional mean is called the regression of $\mathrm{Y}$ on $\mathrm{X}$ estimated conveniently by the method of least squares as in Equation (2). When " $b$ " in Equation (2) is zero (statistically not significant), then an inference is made that $\mathrm{E}[\mathrm{Y} \mid \mathrm{x}]=\mathrm{E}[\mathrm{Y}]=\mu_{\mathrm{y}}$, which implies that the conditional mean is equal to the unconditional mean. In this case, no additional information is obtained about the mean of $\mathrm{Y}$ by observing $\mathrm{X}$.

2. The functional form introduced in Equation (1) to detect convergence of growth rates of eamings of the industrial sectors differs from the functional forms used customarily in research on income inequality. Its estimation is in Equation (1), where both the " $\mathrm{X}$ " and " $\mathrm{Y}$ " variables are growth rates, the relationship between the two variables is $Y^{\prime}$ ', which is the estimator of the conditional mean. By observing "X" first, it intends to calculate the conditional expectation of "Y," and convergence toward the mean is accomplished if the slope $-1<b<1$ and divergence occurs when $b>1$ or $b<-1$.

The other functional forms look at convergence in terms of income and its growth or in terms of a measure of inequality and its trend over time. In the 
former situation, " $\mathrm{Y}$ " is growth rate and " $\mathrm{X}$ " is per capita income and the functional form is either linear or quadratic. In this case, convergence occurs if the slope of the linear equation $b<0$ so that in advanced economies, as income rises the growth of income declines, implying that the poorer states or countries catch up. The quadratic version, on the other hand, tries to detect a renewal of divergence whereby $b_{1}<0$ (coefficient of the linear term) and $b_{2}>0$ (coefficient of the quadratic term), resulting in a $U$ shaped curve.

When measures of inequality, such as the variance, the coefficient of variation, the Gini coefficient and the like, are employed for the " $Y$ " variable, the " $\mathrm{X}$ " variable is time. Linear and quadratic equations are also used, and if the coefficients take on appropriate signs (positive, negative), the quadratic relationship may give rise to Kuznets's inverted U model.

3. Barro and Sala-i-Martin $(1991,1992)$ approached convergence by use of cross-sectional data on state's per capita income or product in terms of the stability of a convergence coefficient $\beta$ such that the per capita income or product approach stability if $\beta$ stabilizes over time. In a comment on their 1991 work, Blanchard $(1991,169-170)$ suggests the use of a procedure similar in methodology to the one employed in this paper.

4. Regions of the United States according to the Bureau of Economic Analysis are (1) New England: CT, NH, ME, MA, RI, VT; (2) Mideast: DE, DC, MD, NJ, NY, PA; (3) Southeast: AL, AR, FL, GA, KY, LA, MS, NC, SC, TN, VA, WV; (4) Far West: CA, NV, OR, WA; (5) Great Lakes: IL, IN, MI, OH, WI; (6) Plains: IA, KS, MN, MO, NE, ND, SD; (7) Southwest: AZ, TX, NM, OK; (8) Rocky Mountain: CO, ID, MT, UT, WY. The first four regions are coastal while the second four regions are interior. Not classified: AK, HI. Although the BEA classification excludes Alaska and Hawaii, those states are included in the Far West region in this paper.

5. The Standard Federal Regions are (1) New England: CT, NH, ME, MA, RI, VT; (2) North Mid-Atlantic: NJ, NY; (3) South Mid-Atlantic: DE, DC, MD, PA, VA, WV; (4) Southeast: AL, FL, GA, KY, MS, NC, SC, TN; (5) Great Lakes: II, IN, MI, MN, OH, WI; (6) Southwest: AR, LA, NM, OK, TX; (7) Central Plains: IA, KS, MO, NE; (8) Rocky Mountain-Northem Plains: CO, MT, ND, SD, UT, WY; (9) Far West: AZ, CA, HI, NV; (10) Northwest: AK, ID, OR, WA. This classification of regions was established in 1972 by executive order to facilitate geographic jurisdiction of field offices of the federal government. 


\section{REFERENCES}

Alonso, William. "Urban and Regional Imbalances in Economic Development." Economic Development and Cultural Change 17 (1968): 1-14.

Amos, Orley M., Jr. "Unbalanced Regional Growth and Regional Income Inequality in the Latter Stages of Development." Regional Science and Urban Economics 18 (1988): 549-566.

. "An Inquiry Into the Causes of Increasing Regional Income Inequality in the United States." The Review of Regional Studies 19 (1989): 1-12. . "Divergence of Per Capita Real Gross State Product by Sector-1963 to 1986." The Review of Regional Studies 21 (1991): 221-234.

Armstrong, Harvey, and Jim Taylor. Regional Economics and Policy. New York: Philip Allan, 1985.

Barro, Robert J., and Xavier Sala-i-Martin. "Convergence Across States and Regions." In Brookings Papers on Economic Activity, edited by William C. Brainard and George L. Perry, 107-158. Washington, D.C.: The Brookings Institution, 1991. . "Convergence." Journal of Political Economy 100 (1992): 223-251.

Blanchard, Olivier Jean. "Comments and Discussion." In Brookings Papers on Economic Activity, edited by William C. Brainard and George L. Perry, 159174. Washington, D.C.: The Brookings Institution, 1991.

Branson, William, and Nikolaos Monoyios. "Factor Inputs in U.S. Trade." Journal of International Economics 7(1977): 111-131.

Browne, Lynn E. "Shifting Regional Fortunes: The Wheel Tums." New England Economic Review (May/June 1989): 27-40.

Bureau of Economic Analysis. "Regional and State Projections of Income, Employment, and Population to the Year 2000." Survey of Current Business 60 (November 1980): 44-71.

Carlino, Gerald A. "Are Regional Per Capita Eamings Diverging?" Business Review-Federal Reserve Bank of Philadelphia (March/April 1992): 3-12.

Congdon, Peter, and John Shepherd. "Components of Social Change in Urban Areas." Urban Studies 25 (June 1988): 173-189.

Creedy, John. Dynamics of Income Distribution. Oxford, England: Basil Blackwell, 1985.

Dowrick, Steve, and Duc-Tho Nguyen. "OECD Comparative Economic Growth 1950-85: Catch-Up and Convergence." The American Economic Review 79 (1989): 1010-1030.

Hart, Peter E., and Robert D. Pearce. "Growth Patterns of the World's Largest Firms." Weltwirtschaftliches Archiv 122 (1986): 65-79. 
Johnson, Kenneth P., John R. Kort, and Howard L. Friedenberg. "Regional and State Projections of Income, Employment, and Population to the Year 2000." Survey of Current Business 70 (May 1990): 33-54.

Kubin, Ingrid, and Michael Steiner. "Labor Market Performance and Regional Types: A Conceptual Framework with Empirical Analysis of Austria." International Regional Science Review 14 (1992): 275-298.

Kuznets, Simon. "Economic Growth and Income Inequality." American Economic Review 45 (1955): 1-28.

Larson, Harold J. Introduction to Probability Theory and Statistical Inference. New York: John Wiley \& Sons, 1982.

Lawrence, Robert Z. "The International Dimension." In American Living Standards: Threats and Challenges, edited by Robert E. Litan, Robert Z. Lawrence, and Charles L. Schultze, 23-65. Washington, D.C.: The Brookings Institution, 1988.

Lewis, Blane D. "The Relative Importance of Exports in Determining Levels of Regional Output and Income: A Model and Empirical Evidence from Kenya." Review of Urban and Regional Development Studies 5 (January 1993): 19-28.

Lienesch, Thomas, and John R. Kort. "The NRIES II Multiregional Macroeconomic Model of the United States." International Regional Science Review 14 (1992): 255-274.

McGillivray, Mark, and Matthew Peter. "Regional Income Inequality in a Developed Nation: A Cross-Sectional Study of Australian Sub-State Regions." The Review of Regional Studies 21 (1991): 137-151.

Miernyk, William H. "Rising Energy Prices and Regional Economic Development." Growth and Change 8(1977): 2-7.

"Energy Availability and State Economic Development." The Journal of Energy and Development 7(1982):163-171.

"Energy and Regional Development." In Energy Costs, Urban Development and Housing, edited by Anthony Downs and Katharine L. Bradburg, 226-286. Washington, D.C.: The Brookings Institution, 1984.

. "Energy Constraints and Economic Development in the Northeast." In Economic Prospects for the Northeast, edited by Harry W. Richardson and Joseph H. Turek, 104-122. Philadelphia: Temple University Press, 1985.

Miller, Rupert G., Jr. Simultaneous Statistical Inference. New York: SpringerVerlag, 1985.

Nelson, Joel I. "Income Inequality: The American States." Social Science Quarterly 65 (September 1984): 854-860.

Niroomand, Farhang. "Factor Inputs and U.S. Manufacturing Trade Structure: 1963-1980." Weltwirtschaftliches Archiv 12(1991): 744-763. 
Park, Siyoung, and Lawrence T. Lewis. "Development in the Location of Selected Computer-Related Industries in the United States." Growth and Change 22 (1991): 17-35.

Ram, Rati. "Kuznets's Inverted-U Hypothesis: Evidence from a Highly Developed Country." Southern Economic Journal 57 (1991): 1112-1123. . "Interstate Income Inequality in the United States: Measurement, Modelling and Some Characteristics." Review of Income and Wealth 1 (1992): 39-48.

Romer, Paul M. "Two Strategies for Economic Development: Using Ideas and Producing Ideas." Proceedings of the World Bank Annual Conference on Development Economics 1992 (March 1993): 63-91.

Rowley, Thomas D., John M. Redman, and John Angle. The Rapid Rise in State Per Capita Income Inequality in the 1980's: Sources and Prospects. Washington, D.C.: United States Department of Agriculture, January 1991. . "The Role of Nonmetropolitan Economic Performance in Rising Per Capita Income Differences Among States." The Review of Regional Studies 22 (1992): 155-168.

Williamson, Jeffrey G. "Regional Inequality and the Process of National Development: A Description of the Patterns." Economic Development and Cultural Change 13 (1965): 3-45. 